\title{
6 Climate Change, Asian Growth and Food Security in LDCs
}

In low-income countries, food is half of the expenditure of ordinary people. Food security is therefore fundamental to their wellbeing. To date, the main source of food insecurity in LDCs has come from variations in domestic production consequent upon climatic shocks. However, many LDCs are already net importers of food and as their populations urbanise in coastal cities, a growing proportion of their populations will become dependent upon imported food rather than domestic production. This exposes LDCs to a further source of food insecurity, namely shocks to world supply resulting in periods of very high prices.

With the rapid growth of food consumption in the emerging market economies, world food markets are continuously being stretched to meet rising demand. Accentuating this long-term trend towards tighter market conditions, increased climatic volatility is periodically exposing one or other of the major grain-producing regions to shocks that hit output.

In response to such shocks, food prices rise to squeeze down consumption to meet reduced world supply. Foodexporting countries protect themselves from this effect by banning grain exports, as is currently the case in Ukraine. This compounds the problem for food importers. Inevitably, the poorest consumers are the ones who are priced out, and so a world food crisis affects LDCs much more severely than most other countries. The food crisis of 2008 was an instance of such a shock. The emerging global food crisis of 2010 brings together climatic shocks and global sourcing of food. The climatic shock has been a severe drought in Russia. But because Russia is a major global producer, the consequences of the shock are being felt in the coastal cities of LDCs. 


\section{[LDCs'] Exposure through climate change}

agenda on

climate change

LDCs are thus doubly exposed to global warming: through should deterioration in their own climates and through shocks in major food producers. Yet, for the next half century the predominantly

be about climate is set to deteriorate both globally and especially in LDCs. This is going to happen regardless of whether further adaptation rather than mitigation. carbon emissions are satisfactorily curtailed, since the lags between the flow of new emissions and the stock of carbon dioxide in the atmosphere are very long. The climate is set to deteriorate because emissions during the period 1960-2010 were much higher than those during 1910-1960. Beyond 2060 the climate facing LDCs is likely to deteriorate further because of delays in curtailing the future emissions of the industrialised and industrialising parts of the world.

The above facts have an obvious but neglected implication for LDCs: their own agenda on climate change should predominantly be about adaptation rather than mitigation. The rest of the world should have the opposite priority. In the OECD and the EMEs the climate is generally not as hot as in LDCs and so it is not set to deteriorate as much. Further, their economies are not as exposed to changes in climate because they are less dependent upon rain-fed agriculture. While they therefore have less need for adaptation, both the OECD and the EMEs urgently need to curb their emissions. Hence for them mitigation, rather than adaptation, should be the priority.

This fundamental difference in priorities is in danger of being missed because so much of the global discourse on climate change is, in effect, a dispute between the OECD countries and the EMEs as to who should do what on mitigation. EMEs want the OECD to pay for the mitigation they undertake, while OECD countries wish to minimise their own costs. It has been tempting for LDCs to insert themselves as a third party to this dispute, seeking compensation 
from the OECD for their own costs of adaptation and mitigation. However, within the terms of this dispute the overwhelming interest of LDCs is in getting both the OECD and the EMEs to do as much mitigation as possible, rather than to extract as much money as possible. Given the financial constraints on OECD budgets, the bulk of the 'compensation' that LDCs receive for the costs of adaptation is likely, indirectly, to come from OECD aid budgets. LDCs have no effective way of preventing the switch from aid to compensation because OECD countries will not make it explicit: indeed, faced with the charge, they will explicitly deny any link, yet aid budgets will wither as compensation payments rise. LDCs will thus be compensating themselves, while in the process becoming subjected to a new wave of conditionality, this time environmental. Such environmental conditionality brings dangers: it could potentially force LDCs to meet higher standards than the OECD and EMEs are willing to impose on themselves. For example, there are already indications that aid may be withheld from opening coal deposits in LDCs, whereas coalmining is still being expanded in both OECD countries and EMEs. As the main sufferers from continued climatic deterioration, LDCs have a natural authority in trying to broker an agreement between the main remitters. It may not be worth jeopardising this role by insisting on a compensation agenda which is unlikely to be realised.

Potentially, LDCs may be able to make some money from selling mitigation. However, even here there are severe limits. To date, the Clean Development Mechanism has overwhelmingly benefited the EMEs, and particularly China, rather than LDCs. This is partly because, given their rapid industrialisation, the EMEs have many more opportunities for mitigation, and partly because they are better placed to meet the governance standards for mitigation to be verified and certified. 
The key innovation in the science of improving crop varieties has been genetic modification

Turning to the adaptation agenda, which should be the priority of LDCs, this has two components. The sector most adversely affected by climate change is agriculture. Hence, one aspect of adaptation is to reduce the exposure of agriculture to climate change: the other is to reduce the exposure of LDC economies to agriculture.

\section{Adaptation within agriculture}

Agriculture is exposed to climate change because the plants that are grown in each LDC are, by a long process of selection, adapted to grow best in the climatic conditions that are currently prevailing. Hence, for most countries any change in climate is likely to worsen growing conditions until plants adapt. Further, climate change seems likely to increase climatic volatility, with more extreme temperatures, floods and droughts. Plants will therefore be stressed beyond the range of climate in which they can readily survive. Over time plants adapt: the varieties grown in LDCs have changed considerably over the centuries. However, if climate change is rapid, there is a danger that the pace of adaptation achieved by past methods will not be able to keep abreast of it. Hence, there is a need to speed up crop adaptation. The pace of crop adaptation depends on the speed of innovation in crop varieties and how rapidly these new varieties spread among farmers: that is, on research and extension.

The key innovation in the science of improving crop varieties has been genetic modification (GM). There is a strong case for supporting research on GM with public money. Instead, paradoxically, many LDCs, notably in Africa, have banned the adoption of GM. The impetus for this ban was the ban imposed by Europe in 1996. In political terms the European ban is most reasonably interpreted as a standard piece of agricultural protectionism, although as is usual with such protectionism a smokescreen was used, in this case a 
health scare. Europe's own scientific authorities have, however, found no health basis for the ban. As European grain productivity falls progressively further behind that of North America, it seems increasingly likely that the ban will be relaxed, probably country by country. Meanwhile there is a strong case for LDC governments to lift their own bans. Until this is done, GM research on the crops best suited for LDC conditions will not even get started.

Agricultural extension services are organisationally difficult, in part because the performance of staff is hard to monitor. In many LDCs extension services have deteriorated, partly due to chronic underfunding. However, it is not clear that low agricultural productivity is primarily due to farmer ignorance, nor that extension is an effective way of spreading knowledge. It may be more cost effective to use limited public funds to accelerate crop research than to try to rebuild extension services which have proved to be so problematic. However, agriculture is highly location specific and so this choice does not lend itself to generalisation.

\section{Adaptation between sectors}

If LDC agriculture is set to become more subject to climatic shocks, it is sensible also to try to reduce the exposure of LDC economies to domestic agriculture. If food cannot reliably be produced domestically due to climatic shocks, then the economy needs to develop export activities that are not climate sensitive and which can therefore pay for imported food. The larger and more diversified a country's exports, the less vulnerable it is to shocks in domestic food production and the better it can cope with price shocks in global food markets. For most LDCs the options for the expansion of exports are natural resources (as discussed in Chapter 2) and light manufactures (as discussed in Chapter 3). There is also sometimes potential for the export of e-services. Here the key 
The major players in the international

community should not get away with paying lipservice to concerns about food insecurity while adopting policies that deepen the problem. inputs are typically good international telecoms and a good post-primary education system, neither of which are currently adequate in most LDCs. It is important that LDCs do not get stuck with new environmental conditionality that makes it more difficult for them to diversify their economies out of agriculture.

\section{Reducing the risks from global food shocks}

There is little that LDCs can do to reduce the risk of global food shocks, but since LDCs bear the brunt of the consequences, it is worth lobbying for policy improvements in other countries. There are three key actions by other countries that would reduce risks. First, the USA has reduced global food supply through its subsidies for grain used as biofuel. The subsidies inadvertently worsen food insecurity in LDCs. Second, in 1996 the EU banned genetically modified organisms (GMOs). This has reduced productivity growth in European grain production and so again reduced global food supply. It has also impeded Africa from adopting GMOs because of fears of restrictions on African exports. Third, several food-exporting EMEs have imposed export bans at times of high world prices in order to protect their domestic consumers. This is a damaging beggar-thy-neighbour policy. In the short term it pushes prices up further, and in the longer term it reduces agricultural investment in these EMEs and so reduces world supply. Concern over export bans has prompted Ngozi Okonjo-Iweala, Managing Director of the World Bank, to speak out against the current grain export ban by Ukraine. Collectively, LDC governments have the authority to condemn the above polices. The major players in the international community should not get away with paying lip-service to concerns about food insecurity while adopting policies that deepen the problem.

Complementary to advocating policies that raise global 
food production are policies that raise food productivity in LDCs themselves. One such policy, the adoption of GMOs, has been noted above. However, other new policies could also be adopted. For decades LDC governments have attempted to raise the productivity of peasant agriculture. One lesson from these past efforts is that this approach is difficult. In contrast, some EMEs, such as Brazil, have successfully raised agricultural production through the expansion of commercial agriculture. The process of growing crops in the ground is not itself subject to scale economies. However, as agricultural productivity becomes more dependent upon technology, purchased inputs and logistics, commercial organisation starts to have advantages over small-scale farming. There is now strong evidence that small farms are less productive than larger farms. Some LDCs have underutilised land which could be opened to commercial farming on a competitive basis. However, such commercial operations are quite distinct from the geopolitical mega-deals that some governments have attempted to negotiate with LDCs. Such deals are aimed to pre-empt food supplies from the global market so as to achieve food security in the countries that acquire these large tracts of land. They are disadvantageous to LDCs: being non-commercial operations there is no reason to expect that the farming practices they adopt will be efficient. Further, since their rationale is to pre-empt LDC food production at times of global shortage, they worsen LDC food insecurity. 
